\title{
Some statistical characteristics of large deepwater waves around the Korean Peninsula
}

\author{
Kyung-Duck Suh ${ }^{\mathrm{a}, *}$, Hyuk-Dong Kwon ${ }^{\mathrm{a}}$, Dong-Young Lee ${ }^{\mathrm{b}}$ \\ ${ }^{a}$ Department of Civil and Environmental Engineering, Seoul National University, 599 \\ Gwanangno, Gwanak-gu, Seoul 151-744, Republic of Korea \\ ${ }^{\mathrm{b}}$ Climate Change \& Coastal Disaster Research Department, Korea Ocean Research \& \\ Development Institute, Ansan P.O. Box 29, Seoul 425-600, Republic of Korea
}

\begin{abstract}
The relationship between significant wave height and period, the variability of significant wave period, the spectral peak enhancement factor, and the directional spreading parameter of large deepwater waves around the Korean Peninsula have been investigated using various sources of wave measurement and hindcasting data. For very large waves comparable to design waves, it is recommended to use the average value of the empirical formulas proposed by Shore Protection Manual in 1977 and by Goda in 2003 for the relationship between significant wave height and period. The standard deviation of significant wave periods non-dimensionalized with respect to the mean value for a certain significant wave height varies between 0.04 and 0.21 with a typical value of 0.1 depending upon different regions and different ranges of significant wave heights. The probability density function of the peak enhancement factor is expressed as a lognormal distribution, with its mean value of 2.03, which is somewhat smaller than the value in the North Sea. For relatively large waves, the probability density function of the directional spreading parameter at peak frequency is also expressed as a lognormal distribution.
\end{abstract}

Keywords: coastal structures, design waves, wave direction, wave period, wave spectrum

\footnotetext{
* Corresponding author. Tel.: +82 2880 8760; fax: +82 28732684 .

E-mail addresses: kdsuh@snu.ac.kr (K.-D. Suh), saemaum79@ naver.com (H.-D. Kwon), dylee@kordi.re.kr (D.-Y. Lee)
} 


\section{Introduction}

During the last several decades, there has been a significant increase in the capability of generation, measurement, and analysis of random directional waves. The use of numerical and physical model tests using random directional waves has also been increased. Accordingly, the estimation of design waves and the design of coastal structures are carried out based on directional random wave spectra rather than using the linear regular wave theory and corresponding empirical formulas. On the other hand, reliabilityor performance-based design methods are adopted in the design of coastal structures, in which the distributional characteristics of design variables (e.g. mean and standard deviation of a variable of normal distribution) are important. Therefore, it is necessary to provide the distributional characteristics of random design variables for reliable and optimal design of coastal structures.

There are a number of variables related to coastal structure design using directional random waves. In the present study, firstly we deal with the relationship between significant wave height and period. The statistical variation of significant wave period for a certain significant wave height is also investigated. Secondly, the statistical characteristics of the peak enhancement factor of a frequency spectrum are investigated. Thirdly, we deal with the statistical characteristics of the spreading parameter of a directional spreading function. Used wave data are the field data measured for 6 to 7 years at four locations around the Korean Peninsula, the field data measured for about 12 years along the coast of Japan by the NOWPHAS (Nationwide Ocean Wave information network for Ports and HArbourS) system, and the hindcasted data for 25 years in waters around the Korean Peninsula. The statistical characteristics are analyzed for large waves comparable to design waves. Since rather various topics are dealt with in this paper, the previous studies are described at the beginning of each related section.

\section{Relationship between significant wave height and period}

In the design of coastal structures, the design wave height corresponding to a certain return period such as 30 or 50 years is often determined by statistical analysis of long-term measurement or hindcasting of extreme waves. Then a question arises as to what wave period should accompany the return wave height. The conventional practice is to prepare a scatter diagram of wave periods versus heights and to make a regression analysis. 
Several formulas have also been proposed for the relationship between significant wave height and period. Shore Protection Manual (U.S. Army 1977, p. 3-73, abbreviated as SPM hereinafter) recommends estimating the significant wave period $T_{1 / 3}$ corresponding to the offshore significant wave height $H_{1 / 3}$ using

$$
T_{1 / 3}=3.85\left(H_{1 / 3}\right)^{0.5}
$$

where $T_{1 / 3}$ and $H_{1 / 3}$ are in seconds and in meters, respectively. Note that the coefficient has been changed from 2.13 to 3.85 due to the conversion of the height units of foot to meter. On the other hand, Goda (2003) proposed the following formula for design waves of a coastal structure:

$$
T_{1 / 3}=3.3\left(H_{1 / 3}\right)^{0.63}
$$

This formula was obtained based on Wilson's (1965) formulas, by referring to Toba's (1997) 3/2 power law between wave height and period.

In order to examine the appropriateness of these formulas, we compared them with the field measurement data and hindcasted data.

\subsection{Field data}

First we compared the formulas with the field measurement data collected at four stations (Pohang, Busan, Marado, and Hongdo) around the Korean Peninsula, the locations and information of which are given in Fig. 1 and Table 1, respectively. At each station, a directional waverider buoy was used to collect 1,024 data during 800 seconds every one hour for 6 to 7 years between 1998 and 2004. The buoy contains heave, pitch, and roll sensors, whose signals are converted to surface elevation and two horizontal velocity components for directional spectrum analysis. The directional spectrum analysis was made using the maximum entropy principle of Hashimoto and Kobune (1985). The frequency and directional resolutions were $0.005 \mathrm{~Hz}$ and 1.0 degree, respectively. At all the stations, the shoaling coefficient corresponding to the significant wave period ranges between 0.913 and 1.0. Therefore, the error would be within 9\% if we assume the measured waves to be deepwater waves. The significant wave height and period were calculated from the frequency spectrum as 


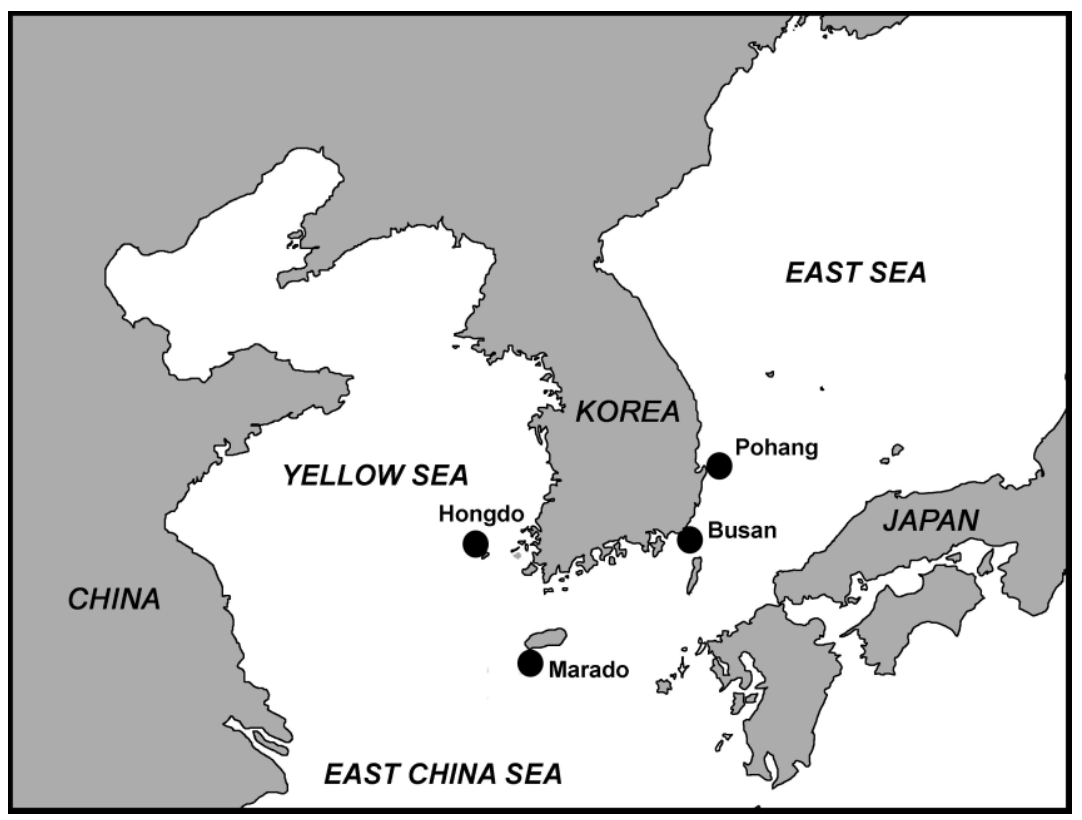

Fig. 1. Location map of wave measurement stations around Korean Peninsula.

Table 1

Details of wave measurement stations around Korean Peninsula

\begin{tabular}{|c|c|c|c|c|c|c|c|c|c|}
\hline Stations & Latitude & Longitude & $\begin{array}{l}\text { Water } \\
\text { depth } \\
\text { (m) }\end{array}$ & $\begin{array}{l}\text { Significant } \\
\text { wave } \\
\text { height }(\mathrm{m})\end{array}$ & $\begin{array}{l}\text { Significant } \\
\text { wave } \\
\text { period (s) }\end{array}$ & $\begin{array}{c}\text { Peak } \\
\text { enhancement } \\
\text { factor }\end{array}$ & $\begin{array}{c}\text { Directional } \\
\text { spreading } \\
\text { parameter } \\
\text { at peak } \\
\text { frequency }\end{array}$ & $\begin{array}{l}\text { Measurement } \\
\text { period }\end{array}$ & $\begin{array}{c}\text { Percentage } \\
\text { of data } \\
\text { collection }\end{array}$ \\
\hline Pohang & $36^{\circ} 05^{\prime} \mathrm{N}$ & $129^{\circ} 33^{\prime} \mathrm{E}$ & 30 & $0.11-9.03$ & $1.84-19.94$ & $0.01-6.18$ & $0.20-144.5$ & $\begin{array}{c}\text { Jan 1, } 1998- \\
\text { Jul 6, } 2004\end{array}$ & 64.64 \\
\hline Busan & $35^{\circ} 04^{\prime} \mathrm{N}$ & $129^{\circ} 06^{\prime} \mathrm{E}$ & 30 & $0.14-8.82$ & $2.64-19.55$ & $0.01-11.32$ & $0.10-145.8$ & $\begin{array}{l}\text { Aug 6, } 1998 \\
- \text { Jul 1, } 2004\end{array}$ & 64.31 \\
\hline Marado & $33^{\circ} 07^{\prime} \mathrm{N}$ & $126^{\circ} 15^{\mathrm{E}}$ & 100 & $0.12-8.84$ & $2.57-19.74$ & $0.01-7.4$ & $0.20-139.5$ & $\begin{array}{c}\text { Apr 15, } 1998 \\
- \text { Dec 21, } \\
2004\end{array}$ & 58.79 \\
\hline Hongdo & $34^{\circ} 44^{\prime} \mathrm{N}$ & $125^{\circ} 11^{\prime} \mathrm{E}$ & 40 & $0.11-5.87$ & $2.14-19.02$ & $0.01-8.8$ & $0.10-131.1$ & $\begin{array}{c}\text { Feb } 18,1998 \\
- \text { Jan } 30, \\
2004\end{array}$ & 71.60 \\
\hline
\end{tabular}




$$
\begin{aligned}
& H_{1 / 3}=4 \sqrt{m_{0}} \\
& T_{1 / 3}=1.14 \sqrt{m_{0} / m_{2}}
\end{aligned}
$$

respectively, where $m_{0}$ and $m_{2}$ are the zero-th and second moments, reapectively, of the frequency spectrum.

Fig. 2 shows comparisons of SPM and Goda formulas with the measured data for the relationship between significant wave height and period. While the variation of significant wave periods is large for smaller significant wave heights, it is reduced with the increase of wave height. Both SPM and Goda formulas follow the lower limit of the measured data if the wave heights are small, and they tend to coincide with the measured data as the wave height increases. This is because the SPM and Goda formulas were proposed for the cases where the wave system is dominated by wind waves. When the wave height is small, the long-period swells coexist with the locally generated wind waves so that the wave period becomes larger than predicted by the SPM or Goda formulas.

Similar comparisons are shown in Fig. 3 for three stations of the NOWPHAS system, which is being operated by the Ministry of Land, Infrastructure and Transport of Japan (Nagai et al., 1994). Most of the data used in the present study were collected for 20 minutes at a sampling interval of $0.5 \mathrm{~s}$ every two hours using various measuring devices from 1991 to 2003. The significant wave height and period of the NOWPHAS system were obtained from the zero-up-cross wave-by-wave analysis method. The information for the three wave stations used in Fig. 3 are given in Table 2. The data contain wave heights larger than in Fig. 2 because of the longer duration of wave measurements. They show similar patterns as those in Fig. 2 except that very large wave periods do not appear for smaller wave heights. For very large wave heights, the Goda formula seems to agree with the measurement data slightly better than the SPM formula. This is also shown at Marado in Fig 2, where relatively large wave heights were observed. Similar plots for other stations of the NOWPHAS system are given in Kwon (2008). Most of them show essentially similar patterns as those in Figs. 2 and 3. 
Table 2

Details of wave measurement stations of NOWPHAS system used in this study

\begin{tabular}{|c|c|c|c|c|c|c|c|}
\hline Stations & Latitude & Longitude & $\begin{array}{l}\text { Water } \\
\text { depth } \\
(\mathrm{m})\end{array}$ & Wave gauge type & $\begin{array}{l}\text { Significant wave } \\
\text { height }(\mathrm{m})\end{array}$ & $\begin{array}{c}\text { Significant } \\
\text { wave period (s) }\end{array}$ & $\begin{array}{l}\text { Percentage } \\
\text { of data } \\
\text { collection }\end{array}$ \\
\hline Sakata & 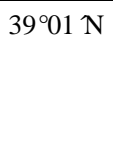 & $139^{\circ} 47^{\prime} \mathrm{E}$ & 45.9 & $\begin{array}{c}\text { Enhanced step-resistance } \\
\text { wave gauge ( } \sim \text { July 1996) } \\
\text { Ultra-sonic wave gauge } \\
\text { (Aug.1996 ) }\end{array}$ & $0.10-9.81$ & $1.90-15.30$ & 85.79 \\
\hline Nakagusuku & $26^{\circ} 14^{\top} \mathrm{N}$ & $127^{\circ} 58^{\prime} \mathrm{E}$ & 46.0 & Ultra-sonic wave gauge & $0.28-10.08$ & $3.60-16.50$ & 90.92 \\
\hline Habu & $34^{\circ} 41^{\top} \mathrm{N}$ & $139^{\circ} 26^{\prime} \mathrm{E}$ & 29.7 & $\begin{array}{l}\text { Current meter type wave } \\
\text { directional meter }\end{array}$ & $0.38-7.23$ & $4.00-18.00$ & 83.05 \\
\hline
\end{tabular}
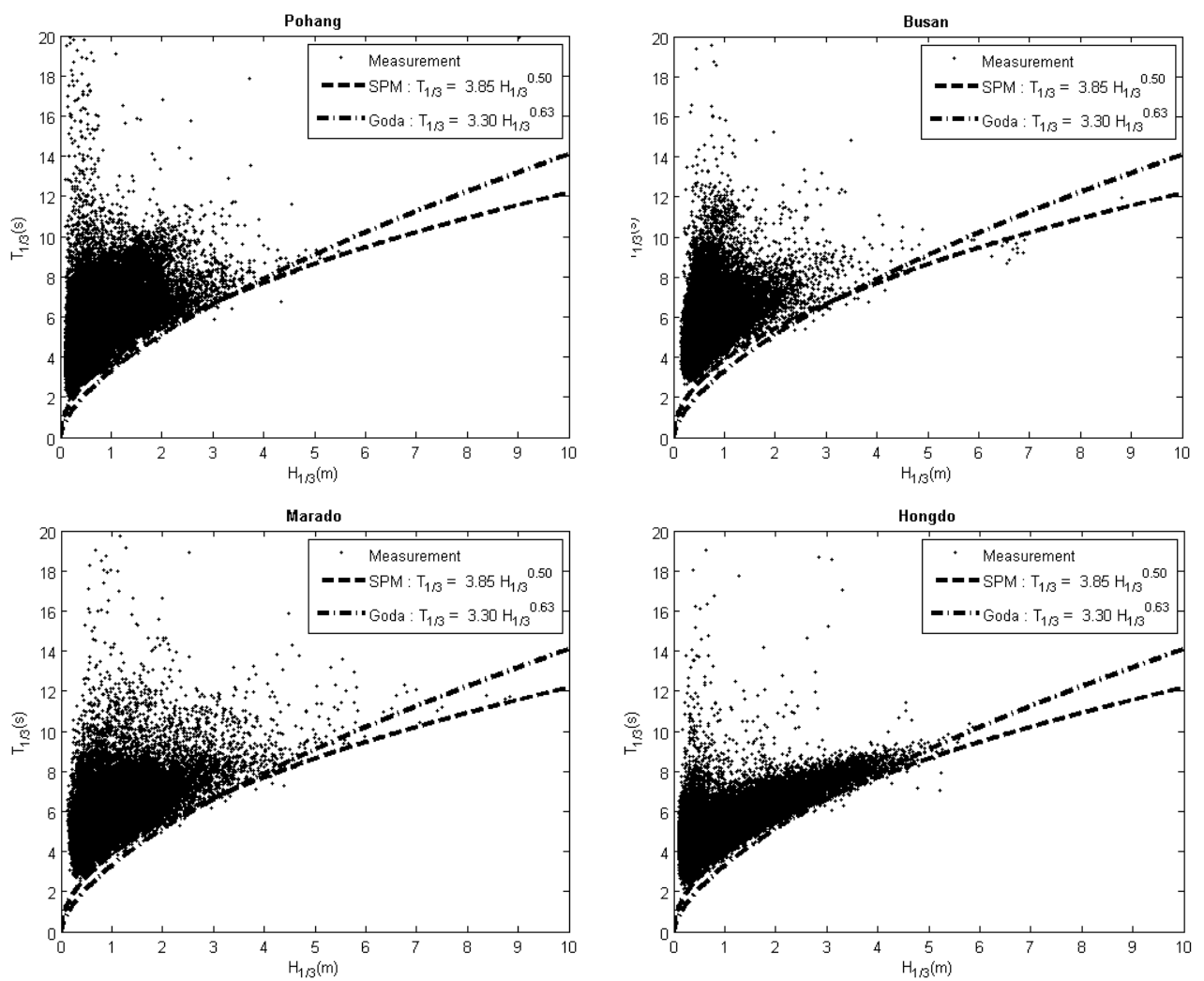

Fig. 2. Relationship between significant wave height and period at stations around Korean Peninsula 


\subsection{Hindcasted data}

The preceding analysis of field measurement data shows that the empirical formulas of SPM or Goda could be used for predicting the significant wave period corresponding to a significant wave height for relatively large waves such as design waves of coastal structures. It may be interesting to compare the hindcasted extreme wave data with the empirical formulas of SPM and Goda. Lee and Jun (2006) established a database of hindcasted wave parameters such as significant wave height, peak period and direction for each grid point of the northeast Asia regional seas with grid size of $18 \mathrm{~km}$. The database contains two sets of data, one for the extra-tropical storm waves for the period of 25 years starting from 1979 and the other for typhoon waves for major 106 typhoons for 53 years since 1951. The HYPA (HYbrid PArametrical) model and the ECMWF (European Center for Medium-range Weather Forecasts) wind data were used for the simulation of waves for the extra-tropical storms, while the WAM model was used for the simulation of typhoon waves using the wind field calculated by the typhoon wind model of Thompson and Cardone (1996) with carefully analyzed typhoon parameters.

They also presented the design wave heights for return period of 50 years at the 106 coastal grid points indicated in Fig. 4. In the present study, we used the annual maximum wave heights and the corresponding wave periods during 25 years from 1979 to 2003 (including typhoon wave data for the same period) at the coastal grid points. The coastal grid points are divided into three groups as shown in Fig. 4 depending on wave characteristics: Yellow Sea, South Sea, and East Sea counterclockwise from the left side of Fig. 4. The large waves along the coasts of Yellow Sea and East Sea are usually generated by extra-tropical storms in winter and spring, while the southern part of Korea is influenced by large typhoon waves in summer and fall. 

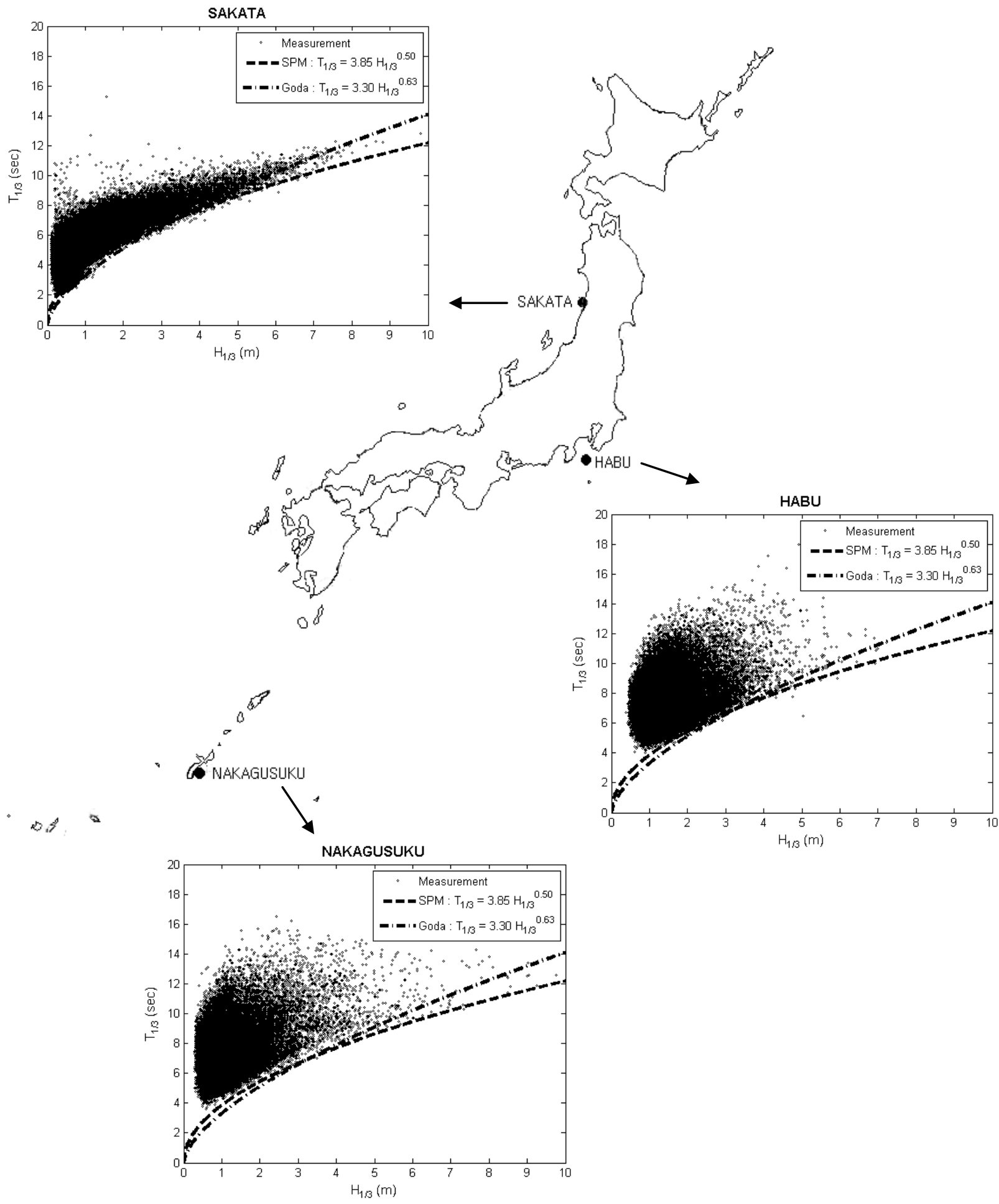

Fig. 3 Relationship between significant wave height and period at several stations of NOWPHAS system 


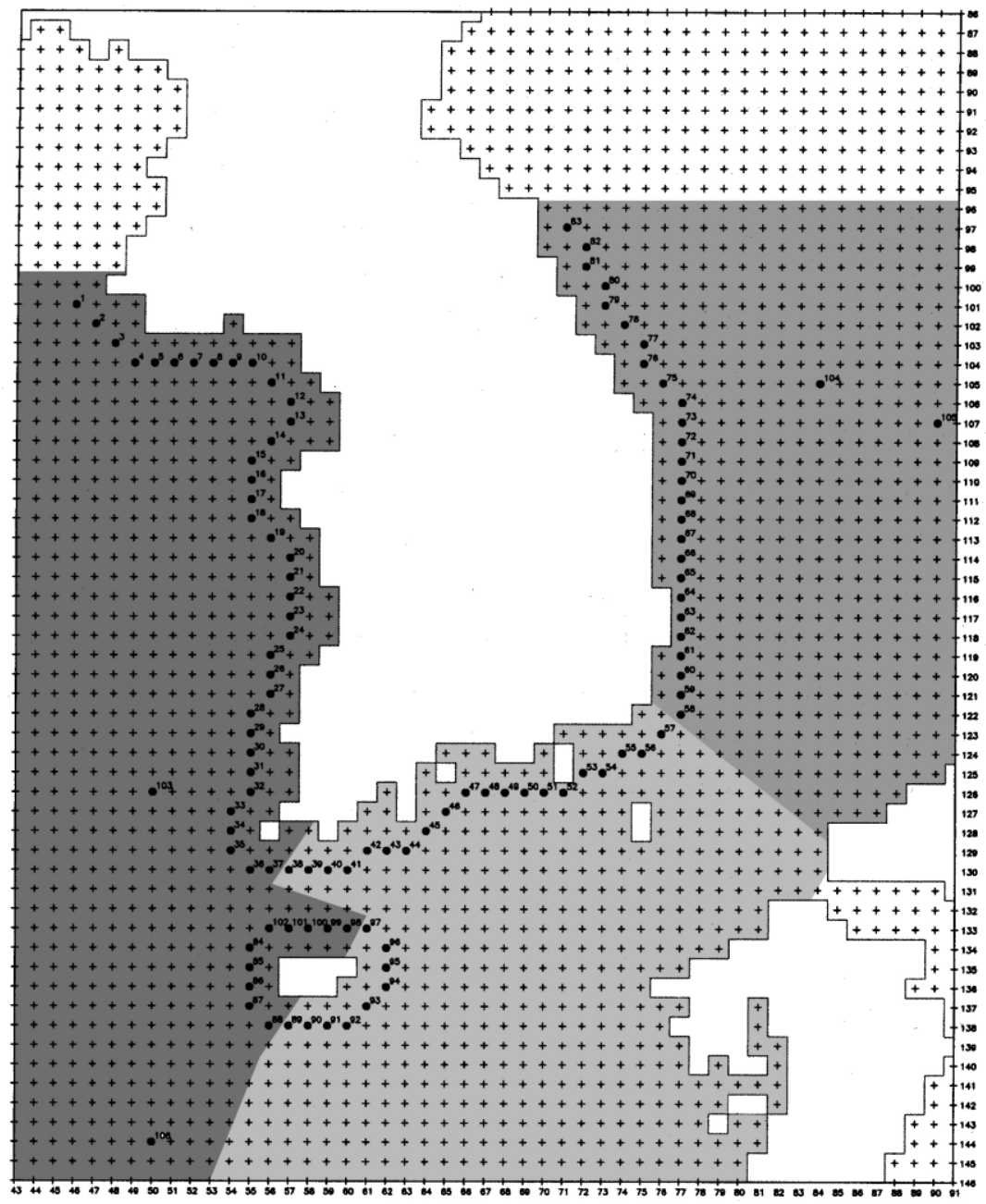

Fig. 4. Coastal grid points for design wave height estimation and regions divided depending on wave characteristics 
Fig. 5 shows the relationship between significant wave height and period of the annual maximum waves. The empirical formulas of SPM and Goda and the curve-fitted lines are also given. The curve-fitted lines were formulated in the form of $T_{1 / 3}=a H_{1 / 3}^{b}$ like the SPM or Goda formula. As in the cases of field measurement data shown in Figs. 2 and 3, the majority of data locates above the empirical formulas for smaller wave heights, while the data fall between the two empirical formulas for very large wave heights. The empirical formulas assume a sufficiently long duration of wind blowing. However, the hindcasted wave data usually do not satisfy this assumption especially when the wave height is small. This may be the reason why long wave periods appeared in the hindcasted data. For very large wave heights, the curve-fitted lines also locate between the two empirical formulas. Therefore, the average value of the SPM and Goda formulas could be used for determining the design wave period corresponding to a design wave height in the case where long-term measurement or hindcasting of wave data is not available.
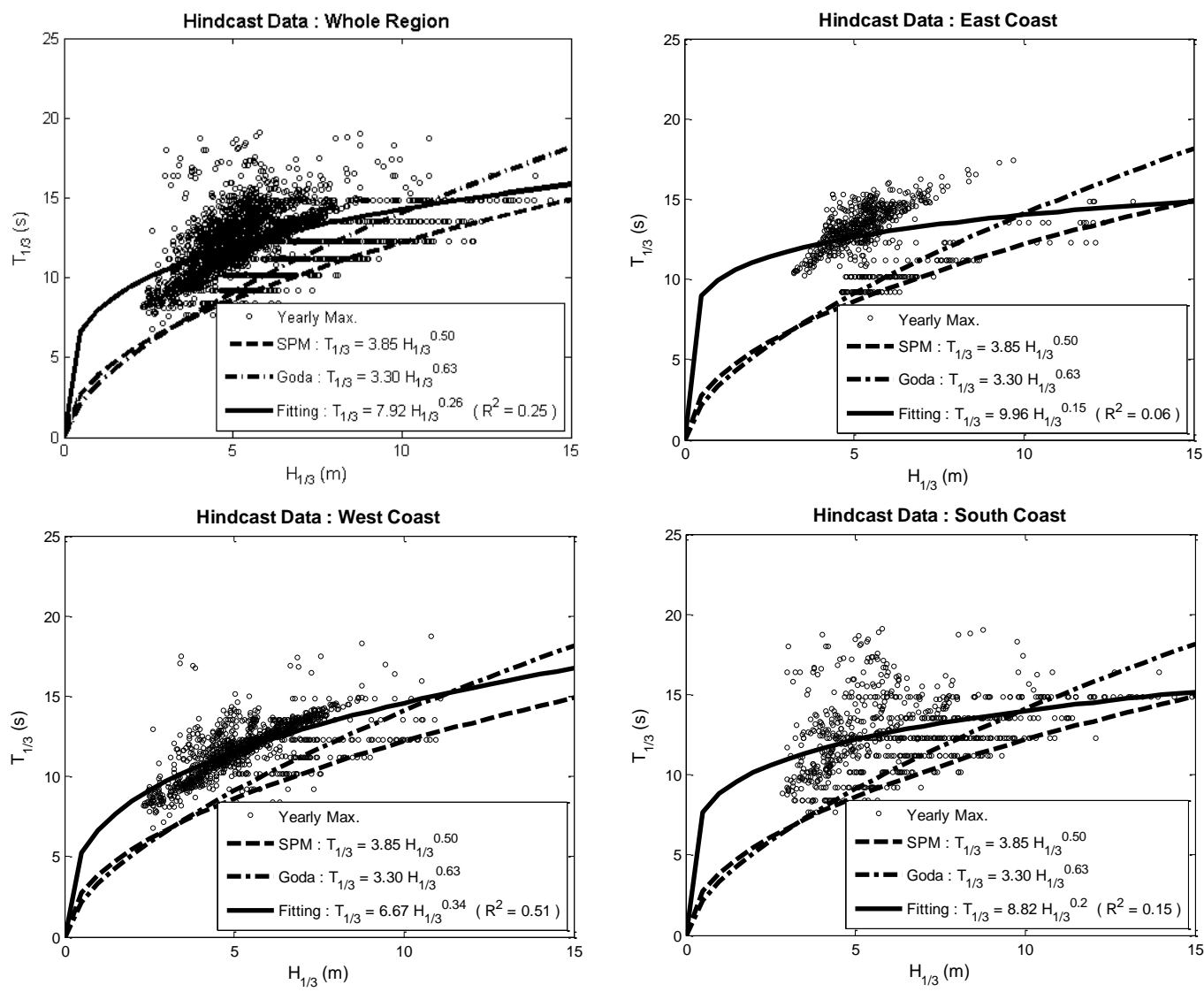

Fig. 5. Relationship between significant wave height and period of hindcasted annual maximum waves 
It is observed the hindcasted data in Fig. 5 are lined on the horizontal lines. This is because the periods of typhoon waves refer to the spectral peak period rather than the significant wave period. The spectral peak period, $T_{p}$, was converted to the significant wave period by the relationship, $T_{1 / 3}=0.95 T_{p}$. In the WAM model, a sparse frequency resolution is used to calculate wave interactions among different frequency components. If the significant wave period was calculated from its relationship with the mean period, which can be calculated using the zeroth and second moments of the frequency spectrum, the line-up problem could be avoided.

\subsection{Variability of significant wave period}

In the performance-based design of coastal structures, the significant wave period corresponding to a significant wave height has been determined by assuming a constant wave steepness (Hanzawa et al. 1996; Goda and Takagi 2000; Suh et al. 2002; Hong et al. 2004) or by using an empirical formula like Eq. (2) (Goda 2001). Both methods do not consider the statistical variability of wave period for a certain wave height, even though they consider the change of wave period with the wave height. As shown in Fig. 5, however, the significant wave period varies much for a single significant wave height. The degree of variability also changes depending on the regions. A large variation is shown on the south coast where typhoon waves are dominant, while the variation is small on the west coast where large waves are generated by extra-tropical storms of relatively constant wind direction.

Fig. 6 shows the variation of $T_{1 / 3} / T_{1 / 3 F i t}$, i.e., the significant wave period which has been non-dimensionalized with respect to the curve-fitted wave period, for varying significant wave heights. The variation is almost constant on the west coast, while it changes depending upon the significant wave height on the south coast, i.e., large variation for smaller wave heights and vice versa. Fig. 7 shows the histograms of the nondimensionalized significant wave period in different regions and different ranges of significant wave heights. The mean and standard deviation calculated by assuming a normal distribution are also given in the figure and are listed in Table 3. The typical value of standard deviation is 0.1 . On the south coast, however, the standard deviation changes 
between 0.04 and 0.21 depending on the range of significant wave heights. These values could be used for selecting randomly varying significant wave periods in the reliability- or performance-based design of a coastal structure.

\section{Table 3}

Mean and standard deviation of non-dimensionalized significant wave height in different coasts and different ranges of significant wave height

\begin{tabular}{ccccccc}
\hline Coast & \multicolumn{2}{c}{ East } & West & \multicolumn{3}{c}{ South } \\
\cline { 2 - 7 }$H_{1 / 3}(\mathrm{~m})$ & $0-10$ & $10-15$ & $0-15$ & $0-6$ & $6-11$ & $11-15$ \\
\hline Mean & 1.0 & 0.94 & 1.0 & 1.01 & 0.98 & 1.0 \\
S.D. & 0.13 & 0.06 & 0.1 & 0.21 & 0.12 & 0.05 \\
\hline
\end{tabular}

\section{Peak enhancement factor}

Several frequency spectrum models have been proposed: Bretschneider-Mitsuyasu and Pierson-Moskowitz spectra for fully developed wind waves, and JONSWAP and TMA spectra for growing wind waves in deep water and finite-depth water, respectively. Since most of the cases in nature are growing wind waves rather than fully developed seas, and since three out of four stations of our field measurement locate in finite-depth waters, we only consider the TMA spectrum. Bouws et al. (1985) proposed the TMA spectrum by multiplying the JONSWAP spectrum by the Kitaigordskii shape function, which indicates the effect of finite water depth. On the other hand, Goda (2000) proposed the expression for the JONSWAP spectrum in terms of wave height and period. Therefore, the TMA spectrum can be written as

$$
S(f)=\beta_{J} H_{1 / 3}^{2} T_{p}^{-4} f^{-5} \exp \left[-1.25\left(T_{p} f\right)^{-4}\right] \gamma^{\exp \left[-\left(T_{p} f-1\right)^{2} / 2 \sigma^{2}\right]} \phi_{K}\left(\omega_{h}\right)
$$



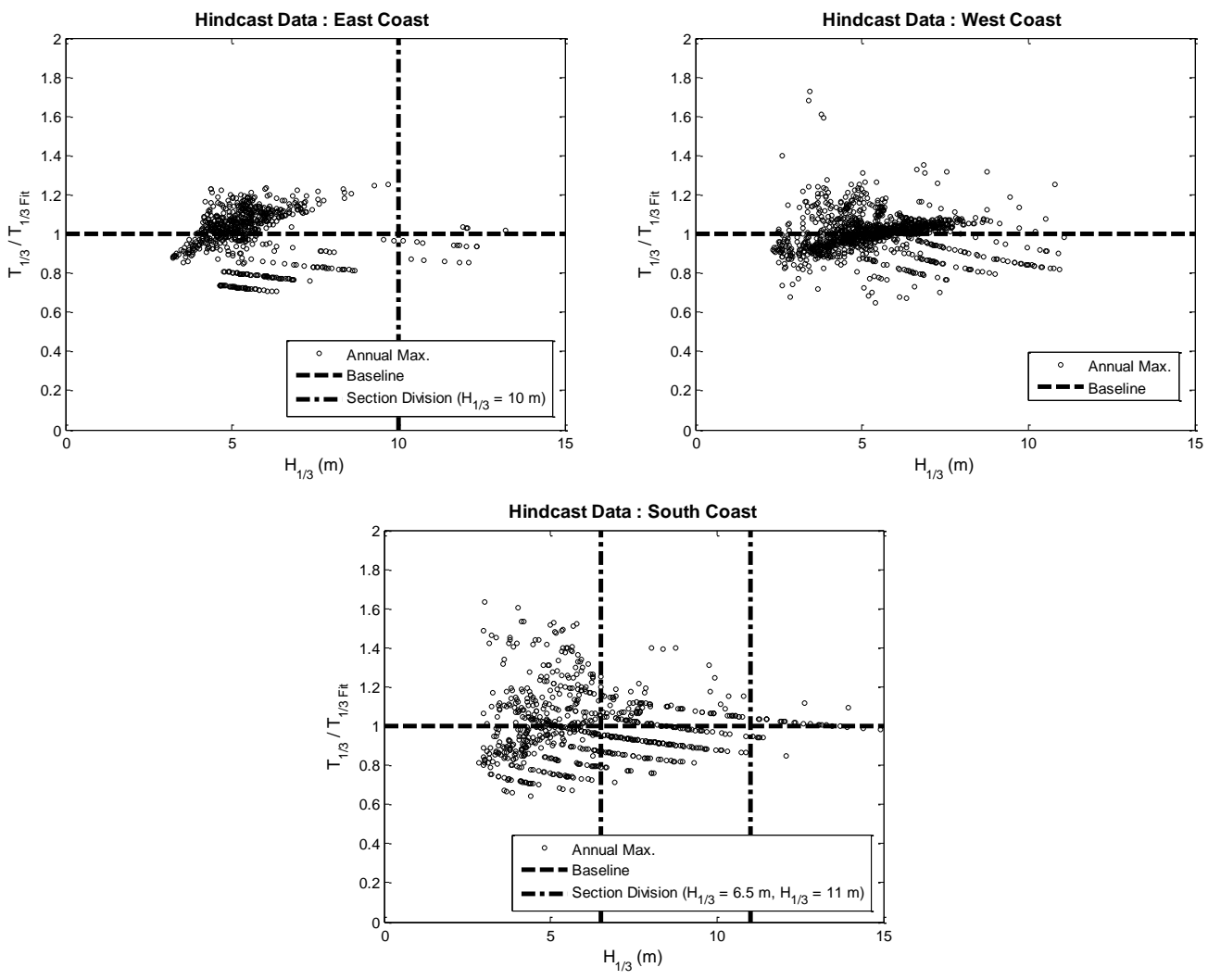

Fig. 6. Non-dimensionalized significant wave period versus significant wave height 

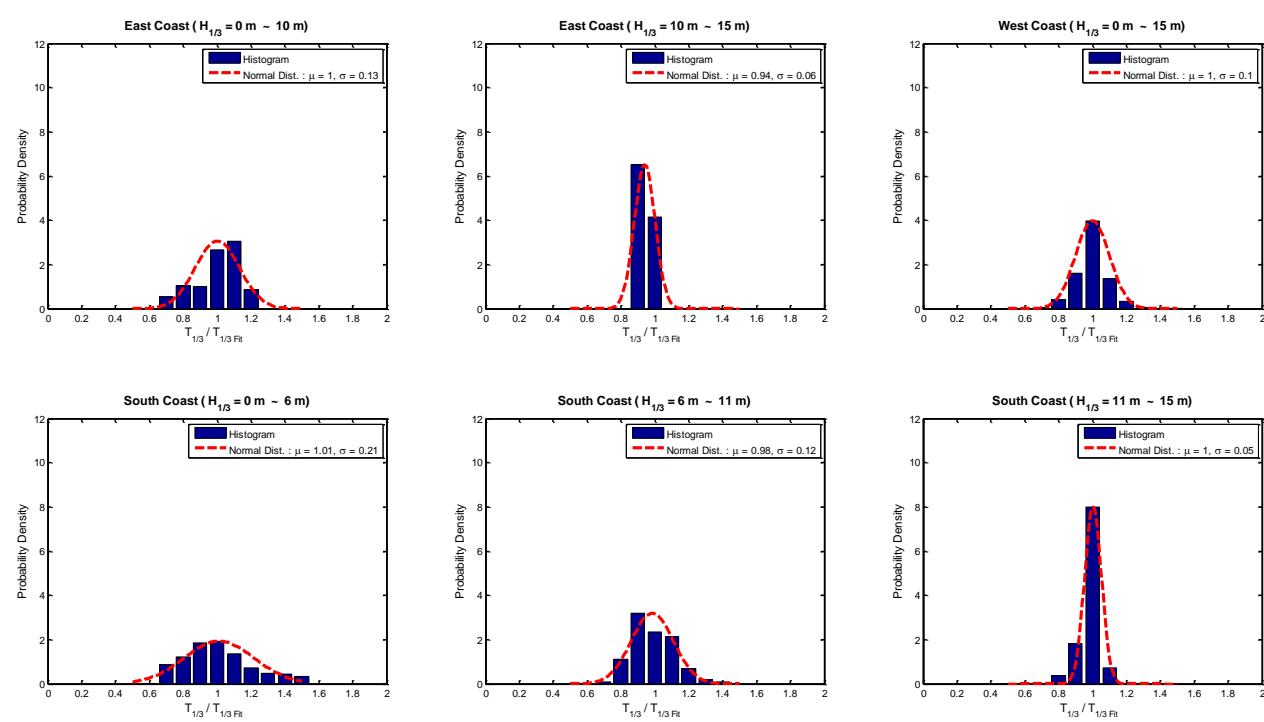

Fig. 7. Distribution of non-dimensionalized significant wave period in different regions and different ranges of significant wave height

where

$$
\begin{aligned}
& \beta_{J}=\frac{0.0624}{0.23+0.0336 \gamma-0.185(1.9+\gamma)^{-1}}(1.094-0.01915 \ln \gamma) \\
& T_{p}=\frac{T_{1 / 3}}{1-0.132(\gamma+0.2)^{-0.55 !}} \\
& \sigma= \begin{cases}\sigma_{a} \approx 0.07, & f \leq f_{p} \\
\sigma_{b} \approx 0.09, & f>f_{p}\end{cases} \\
& \phi_{K}\left(\omega_{h}\right)=\left\{\begin{array}{cc}
0.5 \omega_{h}^{2} & \text { f o } \omega_{h}<1 \\
1-0.5\left(2-\omega_{h}\right)^{2} & \text { f o } \mathbf{t} \leq \omega_{h} \leq 2 \\
1 & \text { f o } \omega_{h}>2
\end{array}\right. \\
& \omega_{h}=2 \pi f(h / g)^{1 / 2}
\end{aligned}
$$

and $\gamma$ is the peak enhancement factor, which controls the sharpness of the spectral peak. The value of the peak enhancement factor is usually chosen as 3.3, which is the mean value determined in the North Sea. Ochi (1979) showed that it is approximately normally distributed with the mean of 3.3 and the standard deviation of 0.79 . 
In order to estimate the variability of $\gamma$, we calculated the values of $\gamma$ of the field measurement data around the Korean Peninsula (see Fig. 1 and Table 1). Fig. 8 shows the scatter plot of $T_{1 / 3}$ versus $H_{1 / 3}$ of the whole data collected at the four locations. Goda's (2003) formula, $T_{1 / 3}=3.3\left(H_{1 / 3}\right)^{0.63}$, is also given. Because we are interested in large windgenerated waves, we only used the data the significant wave height of which is greater than $3 \mathrm{~m}$ and which are located between $T_{1 / 3}=2.8\left(H_{1 / 3}\right)^{0.63}$ and $T_{1 / 3}=3.8\left(H_{1 / 3}\right)^{0.63}$ (see Fig. 8). The numbers of data satisfying these criteria are 60, 48, 185, and 843 at Pohang, Busan, Marado, and Hongdo, respectively.

The peak enhancement factor was determined so as to minimize the root mean squared error between the measured spectrum and the TMA spectrum given by Eq. (5). Fig. 9 shows an example of comparison between measured and curve-fitted frequency spectra.

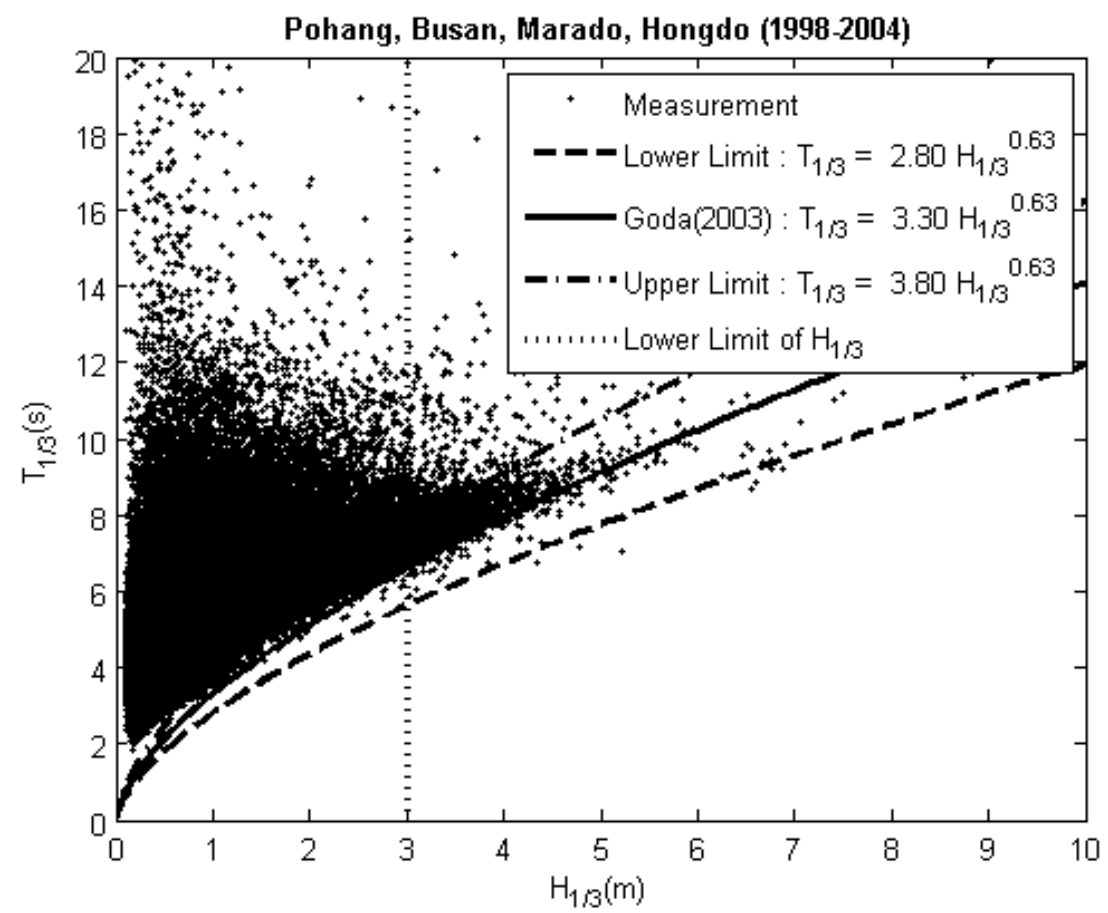

Fig. 8. Definition sketch for selection of wave data used for analysis of peak enhancement factor and directional spreading parameter 


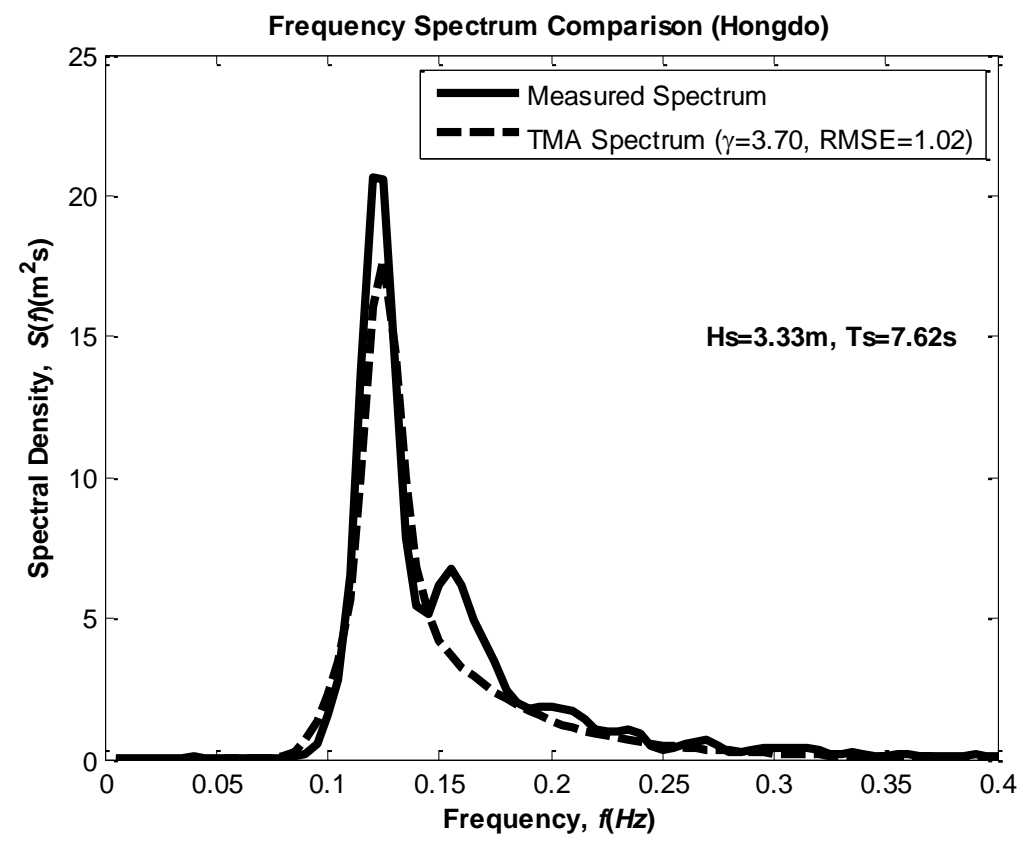

Fig. 9. Example of comparison between measured and curve-fitted frequency spectra

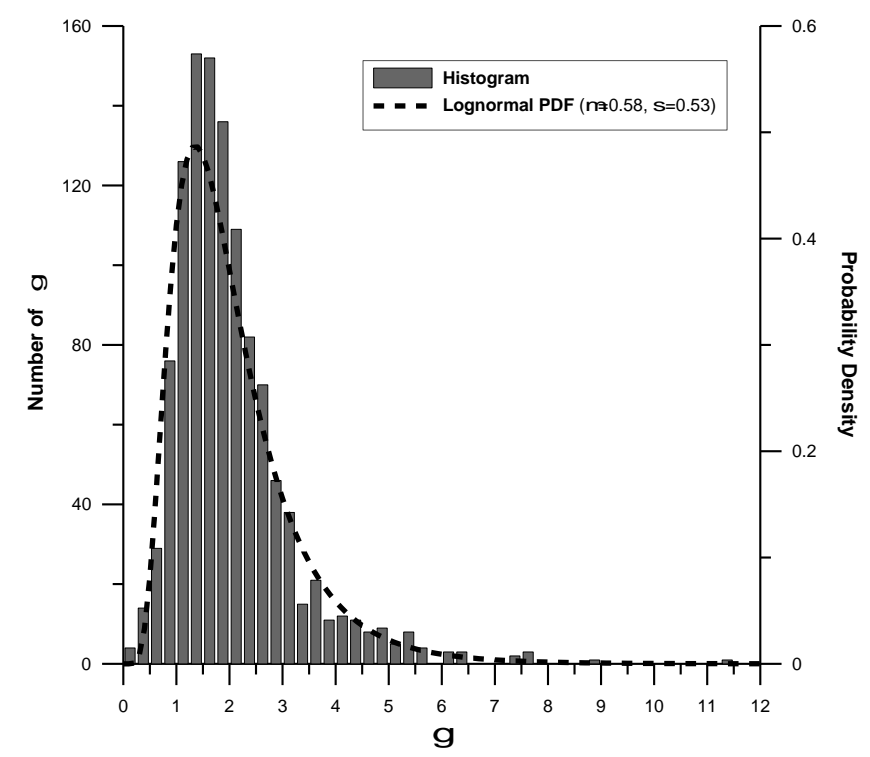

Fig. 10. Histogram and lognormal probability density function of $\gamma$ 
Fig. 10 shows the histogram and probability density of $\gamma$. The lognormal probability density function is also shown and is expressed as follows:

$$
p(\gamma)=\frac{1}{0.53 \sqrt{2 \pi} \gamma} \exp \left\{-\frac{1}{2}\left[\frac{\ln \gamma-0.58}{0.53}\right]^{2}\right\}
$$

This distribution passed the chi-squared goodness-of-fit test of the level of significance of 0.05. The mean of $\gamma$ is 2.03 , which is somewhat smaller than that of the North Sea. Its probability distribution is, however, lognormal rather than normal.

\section{Directional spreading parameter}

A reliable estimation of directional wave properties is a necessary prerequisite in the design of coastal structures. For example, Suh et al. (2002) and Hong et al. (2004) found that the inclusion of the variability in wave direction had great influence on the computed results in the performance-based design of breakwaters. The directional variability they considered includes directional spreading of random directional waves, obliquity of the design principal wave direction from the shore-normal direction, and the variation of principal wave direction about the design value. In the present study, we only deal with directional spreading of random directional waves.

The directional wave spectrum is usually represented as a product of a frequency spectrum and a directional spreading function. The directional spreading function can be modeled using a variety of parametric models. However, the establishment of a standard functional form has not been achieved yet due to either the idealization involved in its formulation or the site-specific nature associated with it. In the present study, we deal with the Mitsuyasu-type function (Mitsuyasu et al. 1975) given by

$$
G(\theta \mid f)=G_{0} \cos 2\left(\frac{\theta-\theta_{p}}{2}\right)
$$

where $f$ is the wave frequency, $\theta$ is the wave direction, $\theta_{p}$ is the principal wave direction, $s$ is the spreading parameter, and $G_{0}$ is a constant given by 


$$
G_{0}=\frac{1}{\pi} 2^{2 s-1} \frac{\Gamma^{2}(s+1)}{\Gamma(2 s+1)}
$$

where $\Gamma$ denotes the Gamma function. Goda and Suzuki (1975) proposed the following expression for the spreading parameter:

$$
s=\left\{\begin{array}{cc}
\left(f / f_{p}\right)^{5} s_{\text {ma }} & f \leq f_{p} \\
\left(f / f_{p}\right)^{-2.5} s_{\text {ma }} & f \geq f_{p}
\end{array}\right.
$$

where $f_{p}$ is the peak frequency, and $s_{\max }$ is the peak value of $s$ at $f=f_{p}$.

Goda and Suzuki (1975) presented a graph of the relationship between $s_{\max }$ and deepwater wave steepness $H_{0} / L_{0}$, where $H_{0}$ and $L_{0}$ denote wave height and length, respectively, in deep water. The relationship given by Goda and Suzuki (1975) is the mean relationship between $s_{\max }$ and $H_{0} / L_{0}$. Actual wave data show a wide scatter around the mean value. In order to estimate the variability of $s_{\max }$, we calculated the values of $s_{\max }$ for the large wind-generated waves indicated in Fig. 8. Fig. 11 shows an example of resolved directional spectrum and the variation of $s$ over the frequency. The directional spreading function and the value of $s$ for each frequency were calculated by the maximum entropy principle of Hashimoto and Kobune (1985). The value of $s_{\max }$ was determined not as the maximum value of $s$ but as the value of $s$ at the peak frequency.

The scatter plot of $s_{\max }$ versus $H_{0} / L_{0}$ is shown in Fig. 12, where the relationship of Goda and Suzuki (1975) is given by a dashed line. Most of the data locate between 0.03 and 0.055 of $H_{0} / L_{0}$ because we only used the selected data as shown in Fig. 8 so that the significant wave height and period are highly correlated. The mean value of measured $s_{\max }$ is somewhat greater than that proposed by Goda and Suzuki (1975). The reason is not known.

The majority of $s_{\max }$ locates between 10 and 40 with the maximum population around 20. The histogram and probability density of $s_{\max }$ is shown in Fig. 13. The lognormal probability density function is also shown and is expressed as follows: 


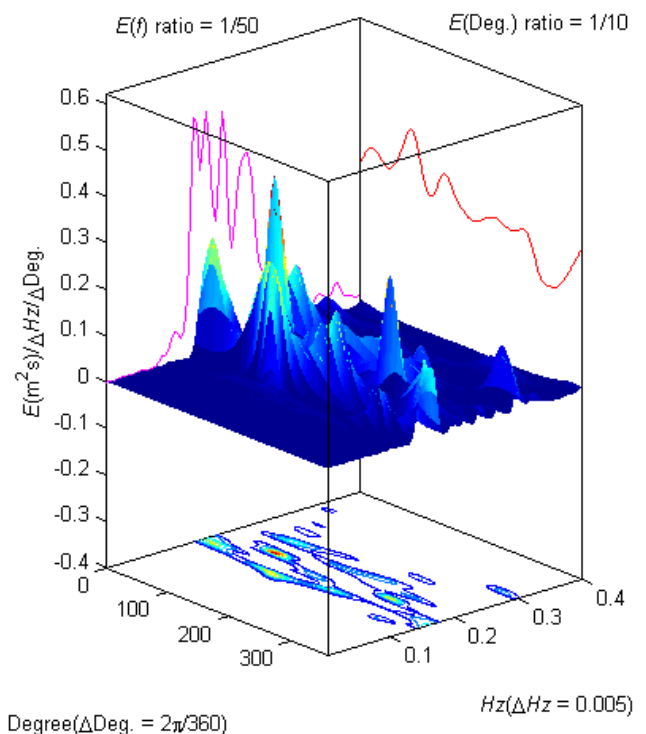

(a)

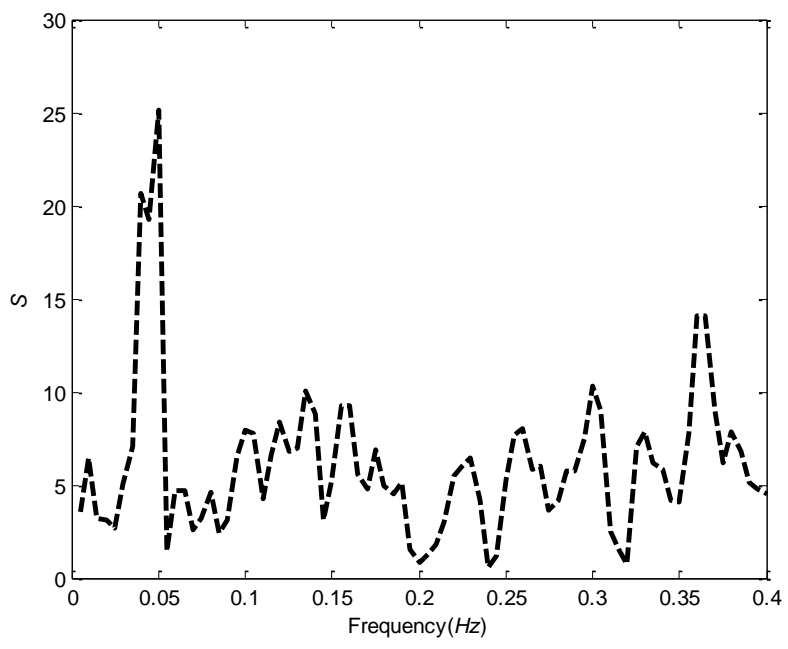

(b)

Fig. 11. Example of (a) resolved directional spectrum and (b) variation of $s$ over frequency 


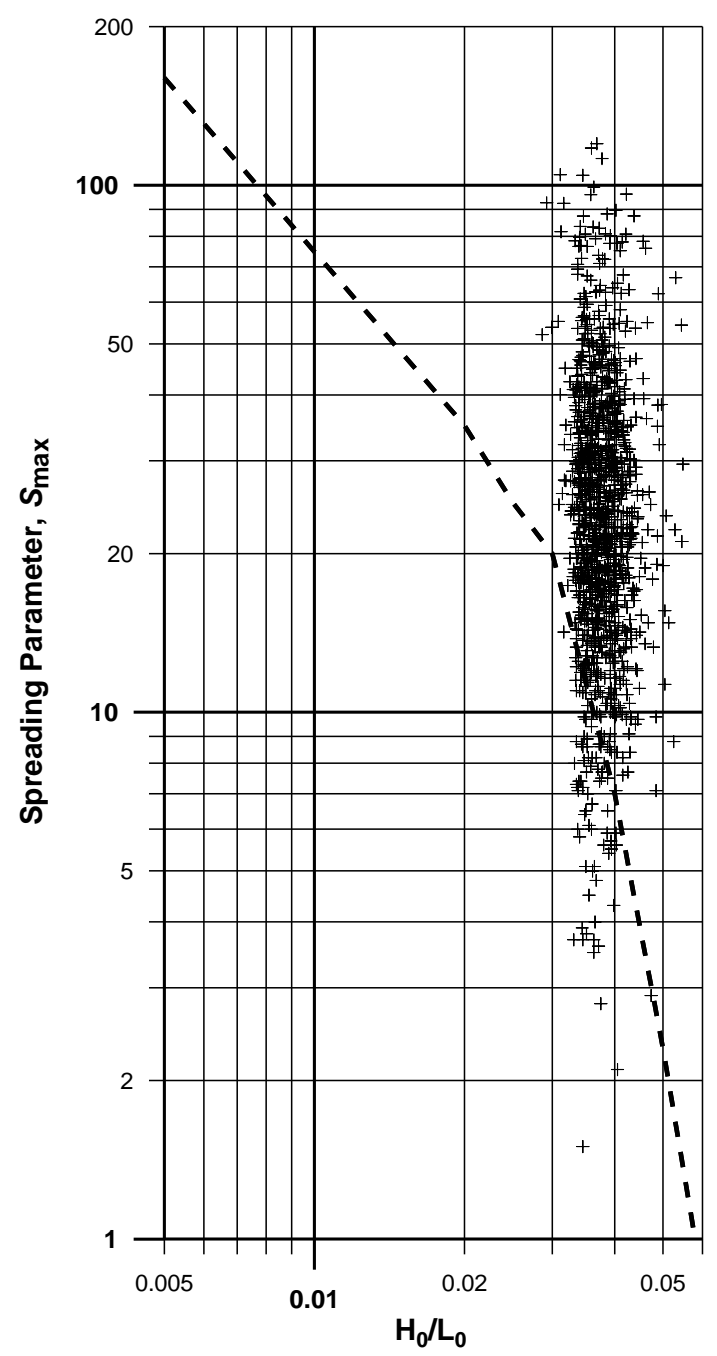

Fig. 12. Relationship between $H_{0} / L_{0}$ and $s_{\max }$ 


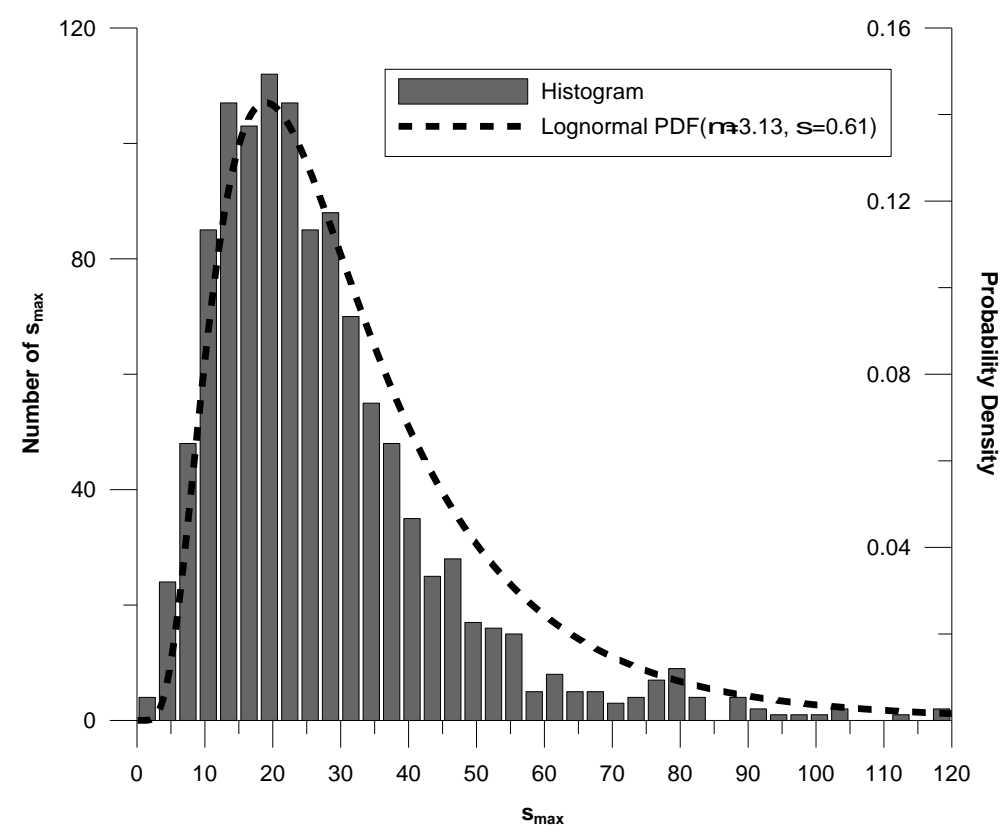

Fig. 13. Histogram and lognormal probability density function of $s_{\max }$

$$
p\left(s_{\max }\right)=\frac{1}{0.61 \sqrt{2 \pi} s_{\max }} \exp \left\{-\frac{1}{2}\left[\frac{\ln \left(s_{\max }\right)-3.13}{0.61}\right]^{2}\right\}
$$

This distribution passed the chi-squared goodness-of-fit test of the level of significance of 0.05 .

\section{Conclusion}

In this study, we investigated the relationship between significant wave height and period, the variation of significant wave period for a certain significant wave height, and the statistical characteristics of peak enhancement factor and directional spreading parameter using various sources of wave measurement and hindcasting data. The investigation was made using relatively large deepwater waves comparable to design waves. Therefore, the results obtained in this study could be used in the design of marine structures in relatively deep waters. They also could be used as deepwater input data for wave transformation modeling in nearshore area. The major findings of the study are as 
follows.

1) For very large waves comparable to design waves, it is recommended to use the average of SPM and Goda formulas for the relationship between significant wave height and period.

2) The standard deviation of significant wave periods non-dimensionalized with respect to the mean value for a certain significant wave height varies between 0.04 and 0.21 with a typical value of 0.1 depending on different regions and different ranges of significant wave heights.

3) The probability density function of the peak enhancement factor $\gamma$ is expressed as a lognormal distribution given by Eq. (11). The mean of $\gamma$ is 2.03, which is somewhat smaller than the value of 3.3 in the North Sea.

4) The probability density function of $s_{\max }$ is expressed as a lognormal distribution given by Eq. (15). The mean value of $s_{\max }$ is somewhat larger than that of Goda and Suzuki (1975). The reason is not known.

\section{Acknowledgments}

This work was supported by the Project for Development of Reliability-Based Design Methods for Port and Harbor Structures and the Project for Storm Surge and Tsunami Prediction Modeling and Estimation of Design Water Level along the Coast of Korea, both sponsored by Korea Ministry of Marine Affairs and Fisheries. This work was conducted at the Engineering Research Institute of Seoul National University.

\section{References}

Bouws, E., Günther, H., Rosenthal, W., Vincent, C. L., 1985. Similarity of the wind wave spectrum in finite depth water 1. Spectral form. J. Geophys. Res. 90 (C1), 975-986.

Goda, Y., 2000. Random seas and design of maritime structures. World Scientific, Singapore.

Goda, Y., 2001. Performance-based design of caisson breakwaters with new approach to extreme wave statistics. Coastal Eng. J. 43, 289-316.

Goda, Y., 2003. Revisiting Wilson's formulas for simplified wind-wave prediction. J. Waterw., Port, Coast. Ocean Eng. 129, 93-95. 
Goda, Y., Suzuki, Y., 1975. Computation of refraction and diffraction of sea waves with Mitsuyasu's directional spectrum. Tech. Note of Port and Harbour Res. Inst. 230 (in Japanese).

Goda, Y., Takagi, H., 2000. A reliability design method of caisson breakwaters with optimal wave heights. Coastal Eng. J. 42, 357-387.

Hanzawa, M., Sato, H., Takahashi, S., Shimosako, K., Takayama, T., Tanimoto, K., 1996. New stability formula for wave-dissipating concrete blocks covering horizontally composite breakwaters. Proc. 25th Coastal Eng. Conf., ASCE, 1665-1678.

Hashimoto, N., Kobune, K., 1985. Estimation of directional spectra from the maximum entropy principle. Rep. Port and Harbour Res. Inst. 24, 123-145 (in Japanese).

Hong, S.Y., Suh, K.D., Kweon, H.-M., 2004. Calculation of expected sliding distance of breakwater caisson considering variability in wave direction. Coastal Eng. J. 46, 119140.

Kwon, H.-D., 2008. Analysis of statistical characteristics of deepwater wave period, direction, and spectrum shape around the Korean Peninsula. Master thesis, Seoul National Univ. (in Korean).

Lee, D.-Y., Jun, K.-C., 2006. Estimation of design wave height for the waters around the Korean Peninsula. Ocean Sci. J. 41, 245-254.

Mitsuyasu, H., Tasai, F., Suhara, T., Mizuno, S., Ohkusu, M., Honda, T., Rikiishi, K., 1975. Observations of the directional spectrum of ocean waves using a cloverleaf buoy. J. Phys. Oceanogr. 5, 750-760.

Nagai, T., Sugahara, K., Hashimoto, N., Asai, T., Higashiyama, S., Toda, K., 1994. Introduction of Japanese NOWPHAS system and its recent topics. Proc. Int. Conf. Hydro-Tech. Engrg. for Port and Harbor Construction, Port and Harbor Res. Inst., Yokosuka, Japan, 67-82.

Ochi, M. K., 1979. A series of JONSWAP wave spectra for offshore structure design. Proc. Int. Conf. Behav. Offshore Struct., 75-86.

Suh, K. D., Kweon, H.-M., Yoon, H. D., 2002. Reliability design of breakwater armor blocks considering wave direction in computation of wave transformation. Coastal Engrg. J. 44, 321-341.

Thompson, E. F., Cardone, V. J., 1996. Practical modeling of hurricane surface wind fields. J. Waterw., Port, Coast. Ocean Eng. 122, 195-205.

Toba, Y., 1977. The 3/2-power law for ocean wind waves and its applications. Advances in coastal and ocean engineering, ed. Philip L.-F. Liu, Vol. 3. World Scientific, Singapore, 31-65. 
U.S. Army Coastal Engrg. Res. Center, 1977. Shore Protection Manual, 3rd Ed. U.S. Government Printing Office, Washington, D.C., USA.

Wilson, B.W., 1965. Numerical prediction of ocean waves in the North Atlantic for December, 1959. Deutsche Hydrographische Zeit 18, 114-130. 